\title{
CD44 is a Marker for the Outer Pillar Cells in the Early Postnatal Mouse Inner Ear
}

\author{
Ronna Hertzano, ${ }^{1}$ Chandrakala Puligilla, ${ }^{2}$ Siaw-Lin Chan, ${ }^{1}$ Caroline Timothy, ${ }^{1}$ \\ Didier A. Depireux, ${ }^{3}$ Zubair Ahmed, ${ }^{4,5}$ Jefrrey Wolf, ${ }^{1}$ David J. Eisenman, ${ }^{1}$ Thomas B. Friedman, ${ }^{6}$ \\ Sheikh Riazuddin, ${ }^{7}$ Matthew W. Kelley, ${ }^{2}$ and Scott E. Strome ${ }^{1}$ \\ ${ }^{1}$ Department of Otorhinolaryngology-Head and Neck Surgery, University of Maryland, 16 South Eutaw Street, Suite 500, \\ Baltimore, MD 21201, USA \\ ${ }^{2}$ Section on Developmental Neuroscience, National Institute on Deafness and other Communication Disorders, National \\ Institutes of Health, Bethesda, MD 20892, USA \\ ${ }^{3}$ Institute for Systems Research, School of Engineering, University of Maryland, College Park, MD 20742, USA \\ ${ }^{4}$ Division of Pediatric Ophthalmology, Cincinnati Children's Hospital Research Foundation, Cincinnati, OH 45229, USA \\ ${ }^{5}$ Department of Ophthalmology, University of Cincinnati, Cincinnati, OH 45229, USA \\ ${ }^{6}$ Section on Human Genetics, Laboratory of Molecular Genetics, National Institute on Deafness and Other Communication \\ Disorders, National Institutes of Health, Rockville, MD 20850, USA \\ ${ }^{7}$ National Centre of Excellence in Molecular Biology, Punjab University, Lahore, Pakistan
}

Received: 18 December 2009; Accepted: 24 February 2010; Online publication: 13 April 2010

\begin{abstract}
Cluster of differentiation antigens (CD proteins) are classically used as immune cell markers. However, their expression within the inner ear is still largely undefined. In this study, we explored the possibility that specific CD proteins might be useful for defining inner ear cell populations. mRNA expression profiling of microdissected auditory and vestibular sensory epithelia revealed $107 \mathrm{CD}$ genes as expressed in the early postnatal mouse inner ear. The expression of 68 CD genes was validated with real-time RT-PCR using RNA extracted from microdissected sensory epithelia of cochleae, utricles, saccules, and cristae of newborn mice. Specifically, CD44 was identified as preferentially expressed in the auditory sensory epithelium. Immunohistochemistry revealed that within the early
\end{abstract}

Electronic supplementary material The online version of this article (doi:10.1007/s10162-010-0211-x) contains supplementary material, which is available to authorized users.

Correspondence to: Ronna Hertzano $\cdot$ Department of Otorhinolaryngology-Head and Neck Surgery - University of Maryland · 16 South Eutaw Street, Suite 500, Baltimore, MD 21201, USA. Telephone: +1410-3286467; fax: +1-410-3286912; email: rhertzano@smail.umary land.edu postnatal organ of Corti, the expression of CD44 is restricted to outer pillar cells. In order to confirm and expand this finding, we characterized the expression of CD44 in two different strains of mice with loss- and gain-of-function mutations in $\mathrm{Fg} / \mathrm{r} 3$ which encodes a receptor for FGF8 that is essential for pillar cell development. We found that the expression of CD44 is abolished from the immature pillar cells in homozygous Fgfr 3 knockout mice. In contrast, both the outer pillar cells and the aberrant Deiters' cells in the Fgfr $3^{P 244 R /+}$ mice express CD44. The deafness phenotype segregating in $D F N B 51$ families maps to a linkage interval that includes $C D 44$. To study the potential role of $\mathrm{CD} 44$ in hearing, we characterized the auditory system of CD44 knockout mice and sequenced the entire open reading frame of $C D 44$ of affected members of DFNB51 families. Our results suggest that CD44 does not underlie the deafness phenotype of the DFNB51 families. Finally, our study reveals multiple potential new cell type-specific markers in the mouse inner ear and identifies a new marker for outer pillar cells.

Keywords: CD44, FGFR3, cochlea, outer pillar cells, deafness 


\section{INTRODUCTION}

The auditory sensory epithelium consists of two types of mechanosensory hair cells and at least six types of supporting cells. The single row of inner hair cells is separated from the first row of outer hair cells by single rows of inner and outer pillar cells. These cells also form the boundaries of a unique fluid-filled structure called the tunnel of Corti, which extends along the length of the cochlear spiral (Raphael and Altschuler 2003). In addition, each outer hair cell is separated from neighboring hair cells by Deiters' supporting cells. The cell bodies of Deiters' cells are located directly adjacent to the basement membrane, and each cell extends a process that interdigitates between the lumenally positioned outer hair cells. Similarly, inner hair cells are surrounded by interdigitations from inner phalangeal cells. Finally, Claudius cells are located on the lateral edge of the last row of outer hair cells and Deiters' cells. All of these cell types are either known or assumed to be essential for hearing (Dror and Avraham 2009).

The molecular factors that regulate hair cell differentiation have been the focus of many studies, and thus far, multiple hair cell-specific markers have been identified. In contrast, although supporting cells have been shown to function in ion recycling, patterning of the organ of Corti, and formation of a cytoskeletal framework for hair cells (Doetzlhofer et al. 2009; Forge and Wright 2002; McKenzie et al. 2004), the specific roles of the individual supporting cells are less well understood. In addition, relatively few supporting cell-specific markers have been characterized. Therefore, the aim of this study was to identify new cell surface proteins that could be used as cell typespecific markers in the mouse inner ear.

Following the advent of fluorescence-activated cell sorting (FACS) in the late 1960s, proteins expressed on leukocytes and identified by at least two different monoclonal antibodies were designated as cluster of differentiation antigens $(\mathrm{CD}$ proteins; Beare et al. 2008; Herzenberg and De Rosa 2000). We explored the possibility that specific $\mathrm{CD}$ proteins might be useful for defining inner ear cell populations. Results of microarray analyses comparing the transcriptomes of early postnatal mouse auditory and vestibular sensory epithelia were interrogated for the expression of $\mathrm{CD}$ genes. We identified and confirmed the expression of $68 \mathrm{CD}$ genes in the early postnatal mouse inner ear using real-time RT-PCR. CD44 was selected for further validation based on a preferential expression in the auditory sensory epithelium and identified as a unique marker for the outer pillar cells in the early postnatal organ of Corti. In order to confirm our findings, we next characterized the expression of $\mathrm{CD} 44$ in mice with a deletion or a gain-of-function mutation of $F g f r 3$ (Hayashi et al. 2007; Mansour et al. 2009), a gene that is involved in pillar cell development. Finally, in order to determine the functional significance of CD44, we investigated in humans and mice a possible role of CD44 in hearing.

\section{METHODS}

\section{Animals and genotyping}

All procedures involving animals were carried out in accordance with the National Institutes of Health Guide for the Care and Use of Laboratory Animals and have been approved by the Animal Care Committee at the University of Maryland, Baltimore. B6.Cg-Cd44 $4^{\mathrm{tm} 1 \mathrm{Hbg}} / \mathrm{J}$ mice were obtained from the Jackson Laboratory (Bar Harbor, ME) and were maintained and genotyped following the Jackson Laboratory guidelines (Protin et al. 1999). A multiplex PCR using oIMR0013-5'-CTT GGG TGG AGA GGC TAT TC-3', oIMR0014-5'-AGG TGA GAT GAC AGG AGA TC-3', oIMR1432-5'-GGC GAC TAG ATC CCT CCG TT-3', and oIMR1433-5'-ACC CAG AGG CAT ACC AGC TG-3' was used to distinguish between the wild-type and mutant alleles (125 and $280 \mathrm{bp}$, respectively). Inner ears from $\mathrm{P} 6 \mathrm{Fg} \mathrm{Fr}^{+/+}$and $\mathrm{Fg} \mathrm{Fr}^{-/}$were obtained as previously described (Puligilla et al. 2007). Inner ears from P7 Fgfr $3^{+/+}$and $F g f r 3^{P 244 R /+}$ were obtained from Dr. S. Mansour (University of Utah, Salt Lake City, UT) after genotyping as previously described (Mansour et al. 2009). Wild-type ICR mice were obtained as time-mated animals from Charles River Laboratories (Germantown, MD).

\section{Gene expression analysis}

For microarray expression analysis, auditory and vestibular sensory epithelia from 2-day-old wild-type C3H mice were dissected and collected separately. Each RNA pool consisted of either cochlear or vestibular sensory epithelia collected from 10 to 12 inner ears. The cochlear sensory epithelia included its underlying mesenchyme, as would be dissected for a regular explant culture. The vestibular sensory epithelia consisted of the saccule, utricle, and two of the three cristae ampullaris (anterior and horizontal) with their surrounding mesenchyme. Total RNA was extracted, processed, and hybridized to mouse Genome 430 version 2.0 Affymetrix microarrays, as previously described (Hertzano et al. 2004), with the exception of adding an amplification step using the Affymetrix two-cycle amplification kit. For PCR and RT-PCR reactions, four separate batches of sensory epithelia of cochleae, utricles, saccules, and cristae were collected from at least 12 ears of $\mathrm{P} 0-\mathrm{P} 2$ mice. We used a thermolysin-assisted dissection to separate the 
epithelium from the underlying cells (Montcouquiol and Corwin 2001). Total RNA was then extracted using the RNeasy Plus Micro Kit (Qiagen, Valencia, CA) after homogenization with QIAshredder columns (Qiagen). The RNA was reverse-transcribed using High-Capacity cDNA Reverse Transcription Kit (Applied Biosystems, Foster City, CA) and evaluated using the RNA 6000 Nano Assay (Agilent Technologies, Santa Clara, CA). All RNA samples used had an RNA integrity number of above 8 (maximal score is 10). To control for possible DNA contamination, the RNA gels were visually screened for high-molecularweight DNA, and PCR primers were designed to span at least one intron. For real-time RT-PCR, we employed a custom-made Taq Man low-density array for 75 genes (for probe names, see Electronic supplementary material (ESM) Table S1). Relative quantification was performed using $P g k 1$ as an endogenous control (Applied Biosystems). All reactions were performed as four independent replicates using an ABI 7900HT real-time RT-PCR instrument. A two-tailed Student's $t$ test was used to compare the relative abundance of the transcripts. For amplification of CD44 isoforms from P0 sensory epithelia, forward and reverse primers were designed in the constant areas of the gene CD44-exon 1F: 5'-CTT CCG TTG GCT GCT TAG TC-3', and CD44-exon19R: 5'-AGC TTT TTC TTC TGC CCA CA-3' PCR products were run on an agarose gel, excised, gel-purified, and cloned into a TOPO TA Cloning ${ }^{\circledR}$ vector (pCR ${ }^{\circledR}$ 2.1TOPO $^{\circledR}$; Invitrogen, Carlsbad, CA). Each insert was confirmed by direct sequencing using the vector $\mathrm{T} 7$ and M13 primers as well as an internal primer CD44_700F: 5'-AGC CCC TCG TGA AGA AGA CT$3^{\prime}$ at the Biopolymer/Genomics Core Facility, University of Maryland, Baltimore.

\section{Immunofluorescence and immunohistochemistry}

Protein detection using immunofluorescence and peroxidase immunostaining was performed on whole mounted cochleae or inner ear sections as previously described (Dabdoub et al. 2008; Hertzano et al. 2004). All primary antibodies were diluted in PBS with $0.1 \%$ Tween-20. For detection of CD44, purified rat antimouse CD44 antibody (BD Pharmigen, San Jose, CA, catalogue no. 550538) was used at 1:200. Secondary detection was performed with a goat anti-rat Alexa-fluor 546 conjugated antibody (Invitrogen) at 1:1,000 or with a biotinylated anti-rat IgG antibody (Vector Laboratories, Inc., Burlingame, CA) followed by reaction with the Elite ABC kit PK-6100 and ImmPACT DAB (Vector Laboratories, Inc.) following the manufacturer's protocol. Images were acquired using a Nikon Eclipse E600 fluorescent microscope (Nikon Instruments Inc., Melville, NY) with a SPOT camera and image acquisition software or with a LSM510 (Zeiss, Thornwood, NY) confocal microscope.

\section{Determination of auditory brainstem evoked potentials}

Auditory brainstem responses (ABR) were recorded from 6-, 12-, and 20-week-old mice after induction of anesthesia using an intraperitoneal injection of $15 \mu \mathrm{l} / \mathrm{g}$ of 2.5\% Avertin (2,2,2 tribromoethanol, Sigma-Aldrich, St. Louis, MO) reconstituted in sterile water. Hearing thresholds were determined at 8,16 , and $32 \mathrm{kHz}$ using an ABR recording system (Tucker-Davis Technologies, Alachua, FL). Recording electrodes were attached to the superior postauricular area of the stimulated ear (-) and the superior postauricular area of the non-stimulated ear (+). A ground electrode was attached to the leg. Eight hundred sweeps of 5-ms-long bursts (shaped with 1-ms onset and offset sinusoidal ramps) were presented to the mouse ear at varying intensities beginning at 94-dB sound pressure level (SPL) and proceeding in 5-dB decrements down to 25-dB SPL. Electrical signals were recorded for $10 \mathrm{~ms}$. Hearing threshold was determined as the lowest intensity at which a definite ABR response pattern could be identified at each frequency. All recordings were performed in a soundproof box (IAC, Industrial Acoustics, The Bronx, NY).

\section{Mutation screening of DFNB51 families}

Primers used for PCR amplification and subsequent sequencing of $C D 44$ were designed from the flanking region of each exon of $\mathrm{CD} 44$ using Primer3 web utility (http://frodo.wi.mit.edu/cgi-bin/primer3/primer3_ www.cgi/). The amplification, sequencing, and mutation analysis were carried out as previously described (Ahmed et al. 2001).

\section{RESULTS}

Multiple $C D$ genes are expressed in the mouse inner ear

In order to identify new cochlear cell type-specific markers, we analyzed a microarray-based dataset comparing the transcriptomes of auditory and vestibular sensory epithelia dissected from early postnatal mice for the expression of $\mathrm{CD}$ genes. We hypothesized that the majority of the genes preferentially expressed in the cochlea are likely to represent supporting cellspecific markers as some of the supporting cells are cochlea-specific. In particular, the pillar cells are unique to the organ of Corti and are essential for hearing (Colvin et al. 1996; Mansour et al. 2009; Puligilla et al. 2007). Out of the 309 mouse CD genes defined at the time of the analysis, 261 had probes on 
the Affymetrix microarray and 107 were detected as expressed based on the Affymetrix MAS 5.0 software (Table 1). Next, 75 genes were selected for validation with real-time RT-PCR based on their expression levels and availability of commercial antibodies. We dissected sensory epithelia from cochleae, utricles, saccules, and cristae of newborn mice. To specifically quantify the relative expression of the genes in the sensory epithelium, the underlying cells, primarily composed of mesenchymal cells, were separated and removed from the epithelia prior to RNA extraction. This was done using a thermolysin-assisted dissection (Montcouquiol and Corwin 2001). The expression of 68 genes was confirmed by real-time RT-PCR (Fig. 1). For validation by real-time RT-PCR, genes were considered as present if their expression could be detected at a cycle threshold lower than 30 .

Three genes had mRNA levels that were significantly higher in the cochlea compared with the vestibular system (defined as greater than twofold in the microarray analysis). These included CD44, Fgfr3 (the mouse ortholog of human FGFR3 also known as CD333), and Jag1 (the mouse ortholog of JAG1 also known as human CD339), which were 6.2-, 11.6-, and 2.7-fold enriched in the cochlea, respectively (Table 1). Fgfr 3 is recognized to be expressed in the developing pillar and Deiters' cells (Peters et al. 1993), while Jag1 expression is restricted to most of the supporting cells in the developing auditory and vestibular systems (Morrison et al. 1999). However, while $C D 44$ was detected by in situ hybridization in the E15 mouse inner ear, it was not studied in later stages of development or associated with specific cell types in the auditory or vestibular sensory epithelia (Yu and Toole 1997). Our real-time RT-PCR results validated the microarray results for all three genes. Specifically, the expression of $C D 44$ was found to be 14- to 40-fold higher in the auditory sensory epithelium compared with the different vestibular sensory epithelia $(p<0.001$, Fig. 1).

Multiple isoforms of $\mathrm{CD} 44$ are preferentially expressed in the mouse auditory sensory epithelium

CD44 is encoded by a gene that encompasses over $90 \mathrm{~kb}$ of genomic DNA and consists of 19 exons (RefSeq NM_009851.2). The first five exons and the last four exons are constant and flank ten alternatively spliced exons. A short isoform of CD44 (CD44s) is the most common transcript of this gene and consists only of the nine constant exons. The alternatively spliced exons are named based on the exons that are spliced in; for example, if alternative exons $8-10$ are included, the isoform is named v8-10. To further characterize the expression of different isoforms of $\mathrm{CD} 44$ in the newborn auditory sensory epithelium, $C D 44$ was amplified using forward and reverse primers from constant exons 1 and 19. Gel electrophoresis of the PCR products revealed four predominant splice isoforms (Fig. 2A). Cloning and direct sequencing of the PCR products identified CD44s (1,155 bp), CD44v6-v10 (1,834 bp), CD44v8-v10 (1,549 bp), and CD44v9-v10 (1,447 bp) as predominantly cochlea-specific (Fig. 2B). The intensity of the PCR band obtained by amplification of CD44s was significantly stronger than the bands for the other isoforms, indicating that the short isoform is most probably the most prevalent one in the newborn mouse inner ear.

\section{CD44 expression in the developing inner ear}

To study the expression of CD44 in the developing mouse inner ear, cross-sections of inner ears from wild-type mice were stained with a CD44 antibody along with the inner ear hair cell-specific antibodies, myosin VI, or myosin VIIa and counter-labeled with 4',6-diamidino-2-phenylindole (DAPI) to detect the cell nuclei and overall tissue architecture (Fig. 3). A low level of CD44 expression was detected in some cells of the inner ear mesenchyme and surrounding otic capsule as early as E14 both in the auditory (Fig. 3A) and the vestibular systems (data not shown). By E16, CD44 expression was detected at a higher level in the mesenchymal cells surrounding the cochlear duct. CD44 was also expressed in the epithelium of the cochlear duct at this time point, medially in the regions of the greater epithelial ridge and laterally in the area of Claudius cells. Neither the hair cells nor the pillar, Deiters, or Hensen cells stained positive for CD44 at E16 (Fig. 3B). At P0, expression of CD44 was detected in the outer pillar cells throughout the cochlear duct, with a stronger expression in the base compared to that in apex (Fig. 3C and data not shown). By P7, CD44 expression was seen in fewer mesenchymal cells. Interestingly, the expression of CD44 increased in intensity in the outer pillar cells and in Claudius cells throughout the length of the cochlear duct. A small number of epithelial cells from the cells medial to the organ of Corti, known as greater epithelial ridge (GER) cells, expressed CD44. In addition, a weak level of expression was also observed in the stria vascularis (Fig. 3D). In the vestibular system, CD44 expression was limited to the mesenchymal cells and otic capsule and was absent in the epithelial layer of the vestibular system at all time points tested (data not shown). Finally, by P24, the expression of CD44 persisted in the epithelial cells medial and lateral to the organ of Corti, but was abolished from the outer pillar cells (ESM Fig. S1). 


TABLE 1

Microarray results for the relative expression of mouse CD genes from early postnatal auditory and vestibular sensory epithelia

\begin{tabular}{|c|c|c|c|c|}
\hline$C D$ & Symbol & Cochlea & Vestibule & $F C$ \\
\hline CD1d1 & $C D 1 d 1$ & 548 & 826 & 0.66 \\
\hline CD1d2 & $C D 1 d 2$ & 110 & 140 & 0.79 \\
\hline CD2ap & CD2ap & 404 & 403 & 1 \\
\hline CD2bp2 & $C D 2 b p 2$ & 420 & 463 & 0.91 \\
\hline CD9 & CD9 & 1,843 & 3,245 & 0.57 \\
\hline CD10 & Mme & 2,428 & 1,320 & 1.84 \\
\hline CD14 & $C D 14$ & 95 & 206 & 0.46 \\
\hline CD16 & Fcr3 & 130 & 470 & 0.28 \\
\hline CD24 & $C D 24 a$ & 3,620 & 2,741 & 1.32 \\
\hline CD26 & Dpp4 & 600 & 900 & 0.67 \\
\hline CD29 & Itgb1 & 490 & 460 & 1.07 \\
\hline CD32 & Fcgr2b & 227 & 330 & 0.69 \\
\hline CD34 & CD34 & 252 & 436 & 0.58 \\
\hline CD38 & $C D 38$ & 111 & 317 & 0.35 \\
\hline CD41 & $\operatorname{ltga} 2 b$ & 158 & 204 & 0.77 \\
\hline CD42c & $G p 1 b b$ & 76 & 48 & 1.58 \\
\hline CD44 & $C D 44$ & 671 & 108 & 6.21 \\
\hline CD45 & Ptprc & 63 & 189 & 0.33 \\
\hline CD47 & Itgp & 550 & 544 & 1.01 \\
\hline CD49c & Itga3 & 237 & 275 & 0.86 \\
\hline CD49f & Itga6 & 1,532 & 1,433 & 1.07 \\
\hline CD51 & Itgav & 1,442 & 1,672 & 0.86 \\
\hline CD53 & CD53 & 48 & 108 & 0.44 \\
\hline CD56 & Ncam & 694 & 720 & 0.96 \\
\hline CD59 & CD59a & 372 & 519 & 0.72 \\
\hline CD66a & Ceacam1 & 86 & 158 & 0.54 \\
\hline CD68 & CD68 & 98 & 400 & 0.25 \\
\hline CD73 & $N+5$ & 648 & 626 & 1.04 \\
\hline CD81 & CD81 & 3,924 & 6,401 & 0.61 \\
\hline CD82 & Kai & 436 & 446 & 0.98 \\
\hline CD83 & $C D 83$ & 230 & 178 & 1.29 \\
\hline CD86 & CD86 & 42 & 109 & 0.39 \\
\hline CD91 & Lrp1 & 1,127 & 1,413 & 0.8 \\
\hline CD97 & CD97 & 166 & 207 & 0.8 \\
\hline CD98 & Slc3a2 & 803 & 1,658 & 0.48 \\
\hline CD9912 & CD9912 & 326 & 328 & 0.99 \\
\hline CD107b & Lamp2 & 4,494 & 5,225 & 0.86 \\
\hline CD108 & Sema7a & 180 & 184 & 0.98 \\
\hline CD109 & CD109 & 43 & 105 & 0.41 \\
\hline CD110 & $\mathrm{Mpl}$ & 87 & 89 & 0.98 \\
\hline CD116 & Csf2ra & 126 & 158 & 0.8 \\
\hline CD117 & Kit & 254 & 380 & 0.67 \\
\hline CD118 & Ifnar & 315 & 328 & 0.96 \\
\hline CD119 & Ifngr & 217 & 282 & 0.77 \\
\hline CD120a & Tnfrsf1a & 834 & 1,123 & 0.74 \\
\hline CD121a & $1 / 1 r 1$ & 144 & 100 & 1.44 \\
\hline CD124 & II4ra & 97 & 101 & 0.96 \\
\hline CD126 & Il6ra & 79 & 74 & 1.07 \\
\hline CD130 & Il6st/gp130 & 867 & 1,292 & 0.67 \\
\hline CD133 & Prom1 & 572 & 732 & 0.78 \\
\hline CD134 & Tnfrsf4 & 92 & 83 & 1.11 \\
\hline CD140a & Pdgfra & 2,857 & 5,310 & 0.54 \\
\hline CD140b & Pdgfrb & 1000 & 976 & 1.02 \\
\hline CD141 & Thbd & 373 & 646 & 0.58 \\
\hline CD142 & F3 & 101 & 385 & 0.26 \\
\hline CD143 & Ace & 225 & 114 & 1.97 \\
\hline CD146 & Mcam & 280 & 329 & 0.85 \\
\hline CD147 & Bsg & 1,482 & 2,171 & 0.68 \\
\hline CD151 & CD151 & 1,378 & 1,574 & 0.88 \\
\hline CD156b & Adam17 & 865 & 863 & 1 \\
\hline
\end{tabular}

\begin{tabular}{cc}
\hline TABLE 1 \\
\hline (continued)
\end{tabular}

\begin{tabular}{|c|c|c|c|c|}
\hline$C D$ & Symbol & Cochlea & Vestibule & $F C$ \\
\hline CDw156c & Adam10 & 2,394 & 2,405 & 1 \\
\hline CD163 & CD163 & 31 & 141 & 0.22 \\
\hline CD164 & CD164 & 3,824 & 4,612 & 0.83 \\
\hline CD164I2 & CD164I2 & 275 & 394 & 0.7 \\
\hline CD166 & Alcam & 250 & 512 & 0.49 \\
\hline CD171 & I1 cam & 101 & 54 & 1.87 \\
\hline CD172a & Ptpns1 & 336 & 365 & 0.92 \\
\hline CD176 & Trf, Tfn & 177 & 872 & 0.2 \\
\hline CD199 & Cmkbr9 & 1,233 & 1,043 & 1.18 \\
\hline CD200 & $O \times 2$ & 427 & 354 & 1.21 \\
\hline CD201 & Procr & 99 & 110 & 0.9 \\
\hline CD202 & Tek & 236 & 242 & 0.98 \\
\hline CD203c & Enpp1 & 248 & 133 & 1.86 \\
\hline CD206 & Mrc1 & 468 & 2,317 & 0.2 \\
\hline CD210 & I/10ra/b & 463 & 466 & 0.99 \\
\hline CD222 & $\lg f 2 r$ & 218 & 183 & 1.19 \\
\hline CD228 & Mfi2 & 1,571 & 2,579 & 0.61 \\
\hline CD230 & Prnp & 1,656 & 3,673 & 0.45 \\
\hline CD232 & Plxnc1 & 365 & 410 & 0.89 \\
\hline CD236r & Gурс & 235 & 350 & 0.67 \\
\hline CD247 & $C D 3 z$ & 285 & 298 & 0.96 \\
\hline CD248 & $C D 248$ & 379 & 347 & 1.09 \\
\hline CD256 & Tnfsf13 & 137 & 238 & 0.58 \\
\hline CD271 & Ngfrap1 & 4,870 & 5,019 & 0.97 \\
\hline CD276 & $C D 276$ & 342 & 314 & 1.09 \\
\hline CD280 & Mrc2 & 585 & 755 & 0.77 \\
\hline CD282 & Tlr2 & 177 & 227 & 0.78 \\
\hline CD292 & Bmpr1a & 2,224 & 2,037 & 1.09 \\
\hline CD298 & Atp1b3 & 1,613 & 3,049 & 0.53 \\
\hline CD302 & CD302 & 1,160 & 688 & 1.69 \\
\hline CD304 & Nrp1 & 799 & 1,015 & 0.79 \\
\hline CD309 & $K d r$ & 133 & 1,046 & 0.13 \\
\hline CD315 & Ptgfrn & 1,092 & 1,224 & 0.89 \\
\hline CD316 & $\operatorname{lgsf8}$ & 753 & 763 & 0.99 \\
\hline CD318 & Cdcp1 & 244 & 301 & 0.81 \\
\hline CD320 & CD320 & 465 & 524 & 0.89 \\
\hline CD322 & Jam2 & 312 & 625 & 0.5 \\
\hline CD324 & Cdh1 & 1,512 & 1,153 & 1.31 \\
\hline CDw325 & Cdh2 & 521 & 454 & 1.15 \\
\hline CD326 & Tacstd1 & 4553 & 6,913 & 0.66 \\
\hline CDw293 & Bmpr1b & 232 & 547 & 0.42 \\
\hline CD331 & Fgfr1 & 638 & 686 & 0.93 \\
\hline CD332 & Fgfr2 & 883 & 1,608 & 0.55 \\
\hline CD333 & Fgfr3 & 1,081 & 93 & 11.62 \\
\hline CD334 & Fgfr4 & 475 & 715 & 0.66 \\
\hline CD338 & Abcg2 & 678 & 779 & 0.87 \\
\hline CD339 & Jag1 & 1,579 & 586 & 2.69 \\
\hline
\end{tabular}

Cells that contain genes with a greater than two-fold mRNA enrichment in the cochlea are marked in bold italics

$C D$ assigned $C D$ for the gene, Symbol gene symbol, FC fold change

To confirm the specificity of CD44 immunolabeling, cochleae from P1 CD44 $4^{+/+}$and $C D 44^{--}$mice were reacted with the antibody for CD44 and expression was detected with enzymatic labeling using a peroxidase-based assay (Fig. 3E-H). We found that CD44 
cochlea $\square$ utricle $\square$ saccule $\square$ crista
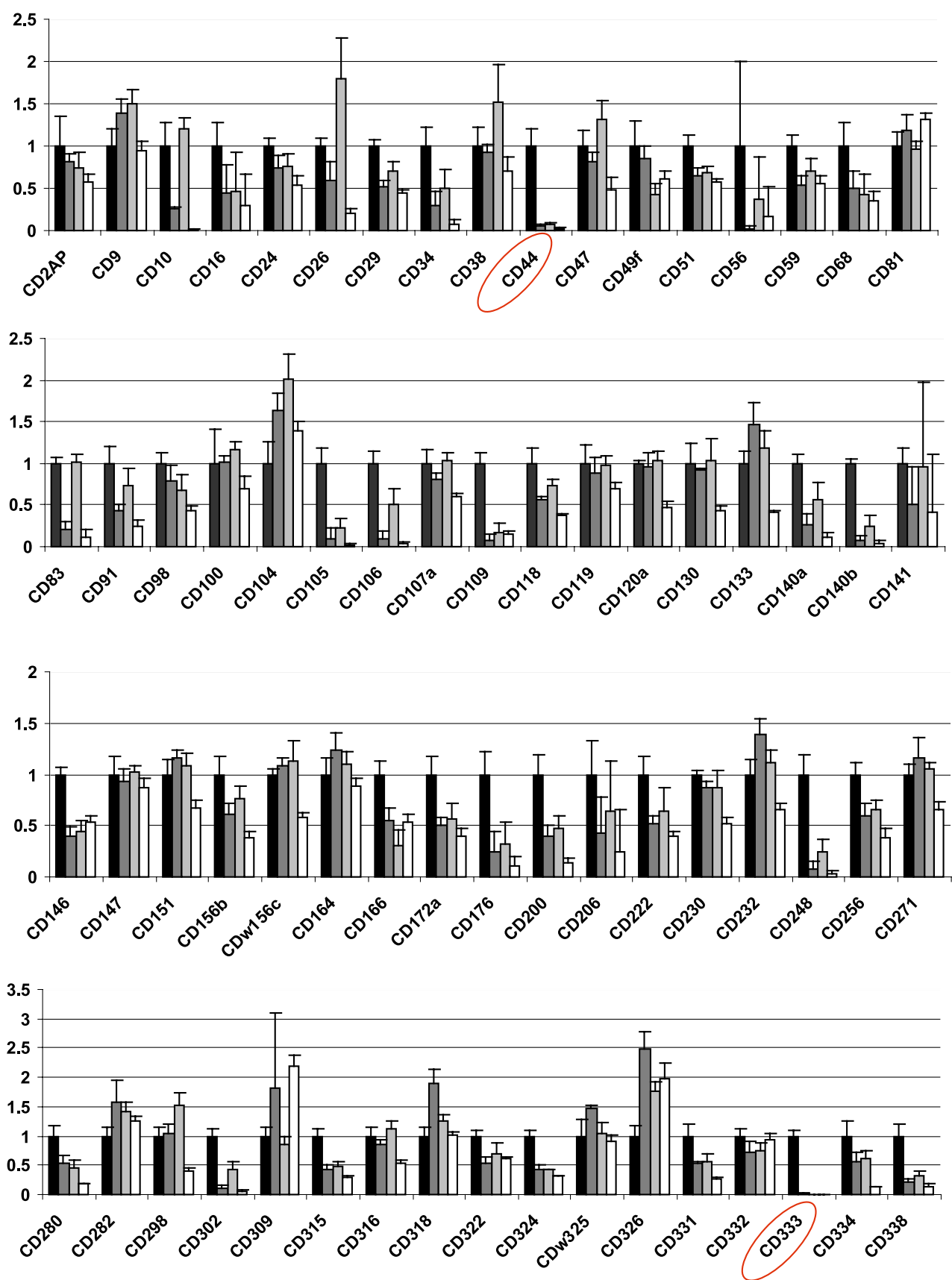

FIG. 1. Relative quantification of $68 \mathrm{CD}$ genes in the newborn mouse inner ear using real-time RT-PCR. All results were quantified relative to the mean expression level in the samples from the cochlear sensory epithelium. The expression of CD44 and CD333 (marked with

specifically stained cells in the greater epithelial ridge, outer pillar cells, and Claudius cells throughout the length of the cochlear duct (Fig. 3E, F). This pattern of expression is consistent with the results that were obtained in sections of $\mathrm{P} 0$ mice. No expression was detected in the ears of the $\mathrm{CD}_{44^{-}}$mice, confirming the specificity of the antibody and staining (Fig. 3G, H). red circles) was greater than tenfold higher in the auditory sensory epithelium compared with the individual vestibular sensory epithelia. Error bars represent one standard deviation. The numerical values for the relative expression results are available in ESM Table S2.

CD44 is a marker for outer pillar cells

To confirm and expand our results, we studied the expression of CD44 in mice with mutations that affect pillar cell development. Pillar cells develop adjacent to the lateral edge of inner and medial edge of outer hair cells. Previous studies have shown that $F g f r 3$ plays 

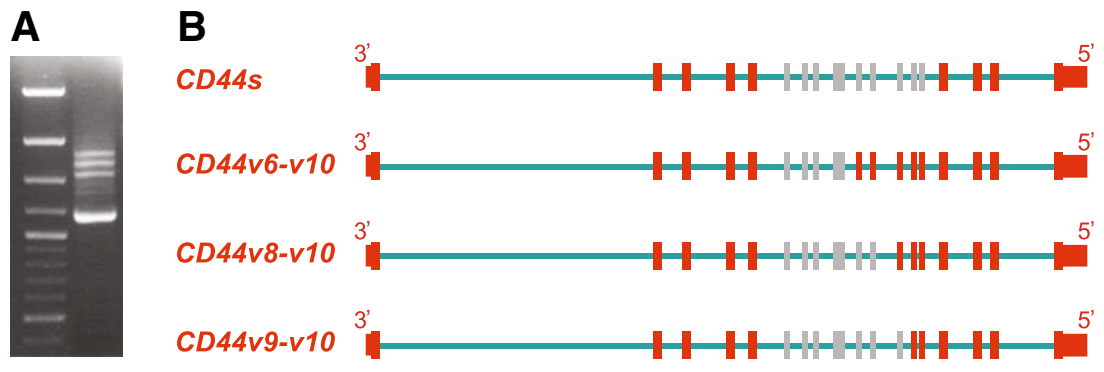

FIG. 2. $C D 44$ isoforms in the newborn mouse cochlea. PCR amplification with $C D 44$-specific primers identified four predominant isoforms expressed in the mouse cochlea (A). Left lane DNA ladder. Isoform sizes: 1,155, 1,447, 1,549 and 1,834 bp. Cloning and direct sequencing of the PCR products identified isoforms CD44s, CD44v6v10,CD44v8-v10, and CD44v9-v10 as the predominant CD44 transcripts expressed in the auditory sensory epithelium (B). a crucial role in cochlear development. In particular, $\mathrm{Fg} f \mathrm{r} 3$ is necessary for the development of pillar cells (Mueller et al. 2002; Puligilla et al. 2007). $\mathrm{Fgfr}^{-/}$mice suffer from hearing loss, most likely secondary to a maturation arrest of their pillar cells, which results as an absence of the tunnel of Corti, among other anatomical abnormalities (Colvin et al. 1996). Gain-of-function mutations in FGFR3 result in hearing loss and skeletal defects in humans and mice (Mansour et al. 2009; Pannier et al. 2009). Specifically, in $F g f r 3^{P 244 R /+}$ mice, a model for Muenke syndrome (MIM 602849; Online Mendelian Inheritance in Man (OMIM), http:/ www. ncbi.nlm.nih.gov/Omim/), and in $\mathrm{Fg} f 3^{\mathrm{Y367C/+}}$ mice, a model for thanatophoric dysplasia type I (TDI-MIM 187600), a Deiters' to outer pillar cell transition has been suggested based on hematoxylin and eosin staining (Mansour et al. 2009) or staining with an antibody against p $75^{\text {NTR }}$ (Pannier et al. 2009).

To assess the efficacy of CD44 as a marker for the outer pillar cells, cochleae from $\mathrm{Fgfr}^{-/-}$and $F g f r 3^{P 244 R /+}$ mice were labeled with an antibody for CD44 (Fig. 4). In P6 Fgfr $3^{-/}$mice, CD44 labeling could not be detected in the region of the outer pillar cell, but persisted in Claudius cells (Fig. 4B). In cochleae of P7 Fgfr $3^{P 244 R /+}$ mice, we observed ectopic expression of CD44. Specifically, the outer hair cells now rested on top of CD44-positive cells. Outer hair cells are normally positioned on top of Deiters' cells, and these cells normally do not express CD44. The aberrant expression of CD44 in Deiters' cells is consistent with the supposition of a Deiters' to outer pillar cell transition in the $F g f r 3^{P 244 R /+}$ mutant mice (Fig. 4D; Mansour et al. 2009).

\section{CD44 is not required for hearing in mice}

Mice homozygous for a targeted deletion of $C D 44$ are obtained at an expected Mendelian ratio and do not suffer from obvious developmental or neurological deficits (Schmits et al. 1997). To determine the function of CD44 in inner ear development, inner ears from early postnatal wild-type and CD44-deficient mice were stained with Alexa-conjugated phalloidin to assess the overall actin cytoskeleton; an antibody that detects Sox2, a supporting cell-specific protein in the early postnatal stages (Hume et al. 2007); antibodies for myosin VIIa and myosin VI, hair cell-specific markers in the mouse inner ear; and an antibody for $\mathrm{p} 75^{\mathrm{NTR}}$ to detect pillar cells (Fig. 5 and data not shown). No specific alterations in the overall architecture or protein expression in the sensory epithelium of the CD44-deficient mice were observed. A single row of inner hair cells and three rows of outer hair cells with uniformly polarized stereocilia were seen throughout the length of the cochlear duct (Fig. 5A, B). Sox2 expression was unchanged between the wild-type and CD44-deficient ears, indicating that all supporting cells are present (Fig. 5C, D). Similarly, myosin VI and p75 expression was similar to the expression in wild-type mice. Analysis of adult mice inner ears stained with phalloidin and an antibody for myosin VIIa showed similar results, indicating that CD44 is not necessary for patterning or survival of cells in the mouse organ of Corti (data not shown).

To determine whether CD44 is necessary for normal hearing, ABR thresholds were determined at 8, 16, and

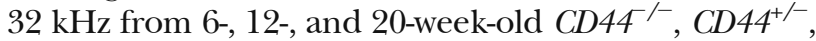
and their wild-type littermate control mice. All mice had clear ABR responses at wild-type levels at 6 weeks of age (Fig. 6A). Auditory thresholds were significantly elevated at $32 \mathrm{kHz}$ in all genotypes measured as early as 12 weeks of age, and by 5 months of age, the majority of the mice had a hearing threshold above 90-dB SPL at $32 \mathrm{kHz}$ (data not shown). ABR morphology at 8 and $16 \mathrm{kHz}$ was within normal limits in all genotypes tested up to 5 months of age (Fig. 6B). There were no statistically significant differences in the hearing thresholds of all three genotypes tested, indicating that CD44 is not necessary for a normal ABR response in mice. 

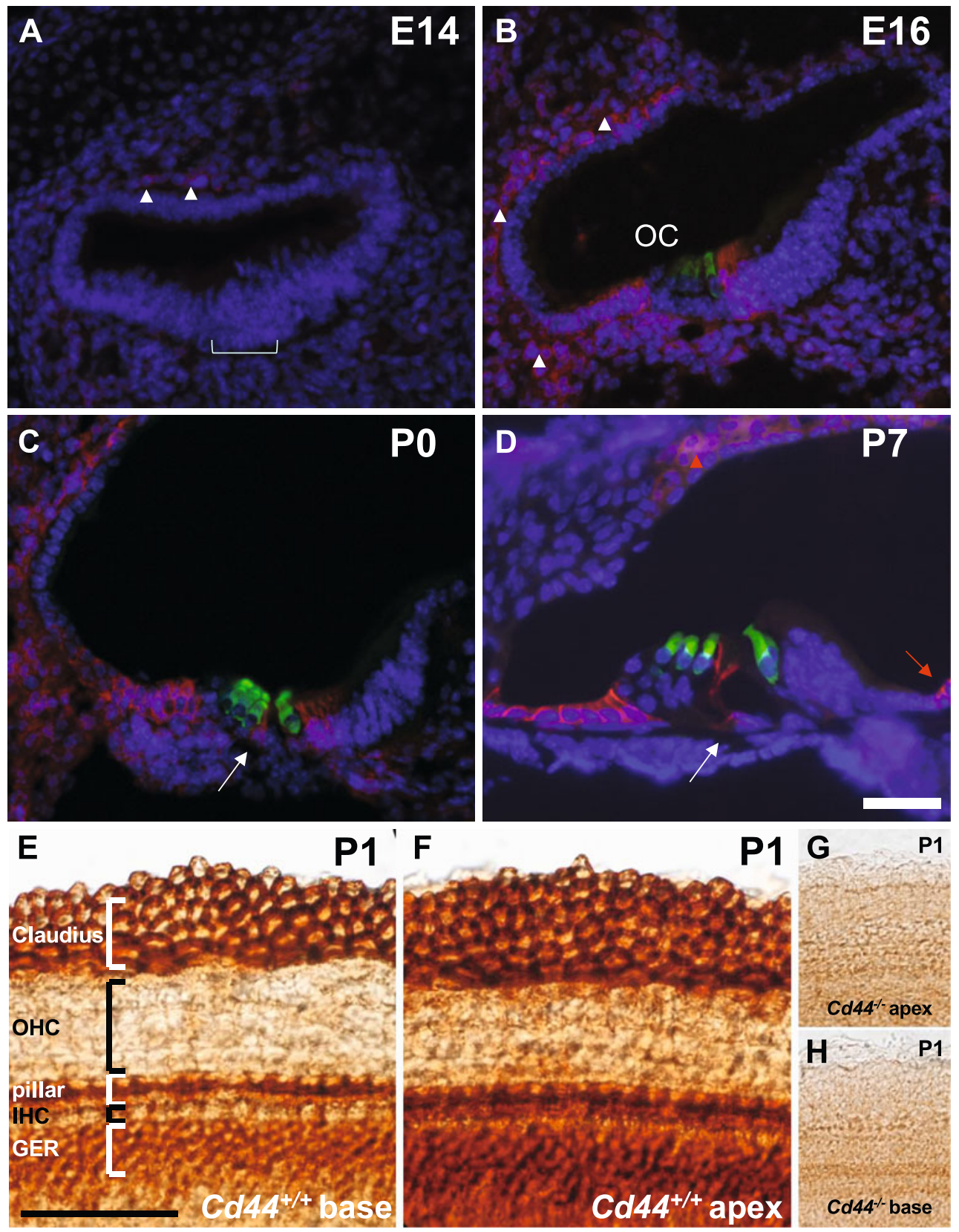

FIG. 3. CD44 expression in the developing mouse inner ear. Crosssections of E14 (A), E16 (B), P0 (C), and P7 (D) wild-type mouse inner ears immunolabeled with CD44 (red) and myosin VI (green) and counterstained with DAPI (blue). CD44 is weakly expressed in some of the mesenchyme surrounding the cochlear duct at E14 (arrowheads; the prospective organ of Corti is marked with a bracket). By E16, the expression of CD44 is increased in the mesenchymal tissue (arrowheads) and is present also in the epithelium of the cochlear duct. Of note, at E16, CD44 expression is not detected in the hair cells, or in the Deiters', Hensen's, or pillar cells. By P0, the expression of CD44 includes the outer pillar cell (arrow). At P7, the expression of CD44 is decreased in the underlying mesenchyme and increases in intensity in Claudius and the outer pillar cells. CD44 can also be detected in the stria vascularis (red arrowhead). A small number of cells in the GER also stain positive for CD44 (red arrow). Whole mount immunodetection of CD44 with DAB staining on P1 cochleae from $\mathrm{Cd} 44^{+/+}(\mathbf{E}, \mathbf{F})$ and $\mathrm{Cd}_{4} 4^{-}$mice $(\mathbf{G}, \mathbf{H})$ shows that the CD44 antibody, specifically stains the membranes of the CD44 expressing cells as this staining is completely abolished in the $\mathrm{CD}_{44^{-}}$mice. Scale bar, $50 \mu \mathrm{m}$ (A-F). OHC outer hair cells, IHC inner hair cells, GER greater epithelial ridge, $O C$ organ of Corti.

\section{CD44 maps to DFNB51}

To determine whether CD44 could underlie human hereditary non-syndromic hearing loss, we searched the Hereditary Hearing Loss Homepage (http://

webh01.ua.ac.be/hhh/) for deafness loci that map to 11pter-p13. We found that $C D 44$ is located within the linkage interval of DFNB51. The DFNB51 locus was defined based on genetic linkage data from two consanguineous families from Pakistan (PKDF240 

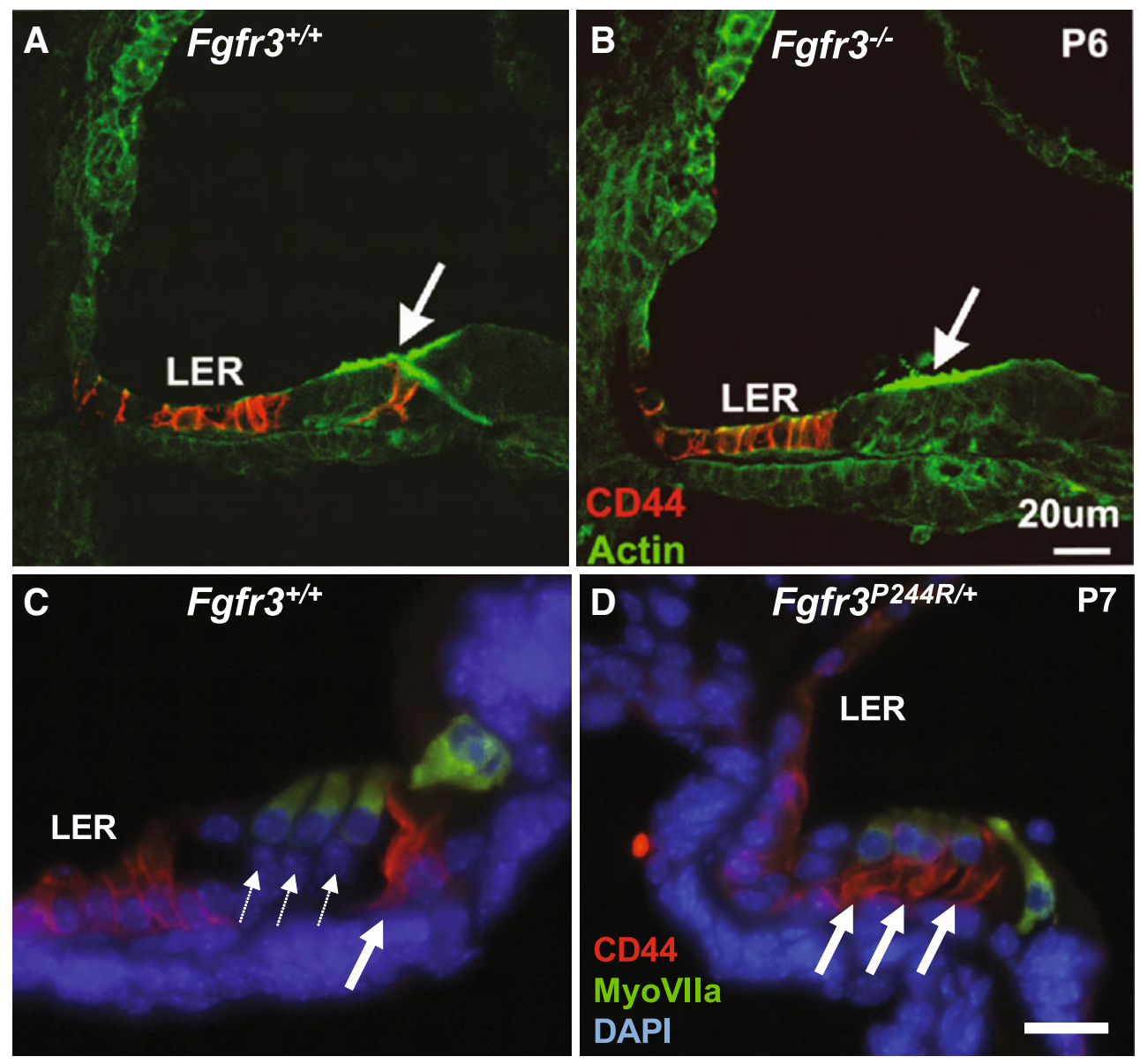

FIG. 4. CD44 specifically stains the outer pillar cells. A, B Crosssections of P6 Fgfr ${ }^{+/+}$(A) and $\mathrm{Fgfr}^{-/}$cochleae (B) immunolabeled with antibodies against CD44 (red) and phalloidin (green). The CD44 staining is completely lost from the outer pillar cell, but not from the lesser epithelial ridge cells $(L E R)$ in the $F g f r 3^{-1-}$ cochlea. C, D Crosssections of $\mathrm{P} 7 \mathrm{Fgfr}^{+/+}(\mathbf{C})$ and $\mathrm{Fgfr} \mathrm{P}^{\mathrm{P} 244 \mathrm{R} /+}$ cochleae (D) immunola-

beled with antibodies against CD44 (red) and myoVIla (green) to mark the hair cells and DAPI to mark the cell nuclei. In the wild-type mice, every outer hair cell is positioned over a Deiters' cell (dotted arrows) (C). In the Fgfr $3^{P 244 R /+}$ mice, the Deiters' cells convert to cells that resemble the outer pillar cells (two left solid arrows) (D) and stain positive for CD44. Scale bar, $20 \mu \mathrm{m}$.

and PKDF407) that segregate recessively inherited, profound congenital deafness (Shaikh et al. 2005).

All of the coding exons of $C D 44$ were sequenced in a deaf and in an unaffected individual from each of the two DFNB51 families. In family PKDF407, we found homozygosity for a nucleotide change of a $\mathrm{G}$ to $\mathrm{C}$ resulting in an arginine to proline substitution (p.R46P) in constant exon 2 of $C D 44$ in all three affected individuals. This change was not identified in family PKDF240. We sequenced 394 alleles and found two heterozygous changes in two normal individual controls. Both individuals are from the same caste as family PKDF407, consistent with p.R46P being a polymorphism. Further investigation showed that p.R46P represents a polymorphism known also as the uncommon Indian (In) blood group antigen allele $\operatorname{In}^{a}$ (Spring et al. 1988). Homozygosity for this allele is rare and has been associated with production of alloantibodies to the common variant of CD44 $\left(I^{b}\right)$ after transfusion or pregnancy.

\section{DISCUSSION}

Cell type-specific markers offer advantages that range from identification of cells by immunolabeling, ability to cell sort and enrich a particular cell type from a heterogenous population, to functional studies of these proteins using mouse models. Specifically, due to their wide use in FACS, there is a large variety of commercially available fluorochrome-conjugated antibodies against $\mathrm{CD}$ proteins that can be used for cell sorting or cell tracking in vivo (Beare et al. 2008). Using a combination of microarray data analysis, comparisons of the expression profiles of auditory and vestibular sensory epithelia from newborn mice, followed by validation with real-time RT-PCR, we have established the expression of $68 \mathrm{CD}$ genes in the newborn mouse inner ear. We focused our study on ears of early postnatal mice. By $\mathrm{P} 0$, most of the cell types of the mouse inner ear are present; however, the 

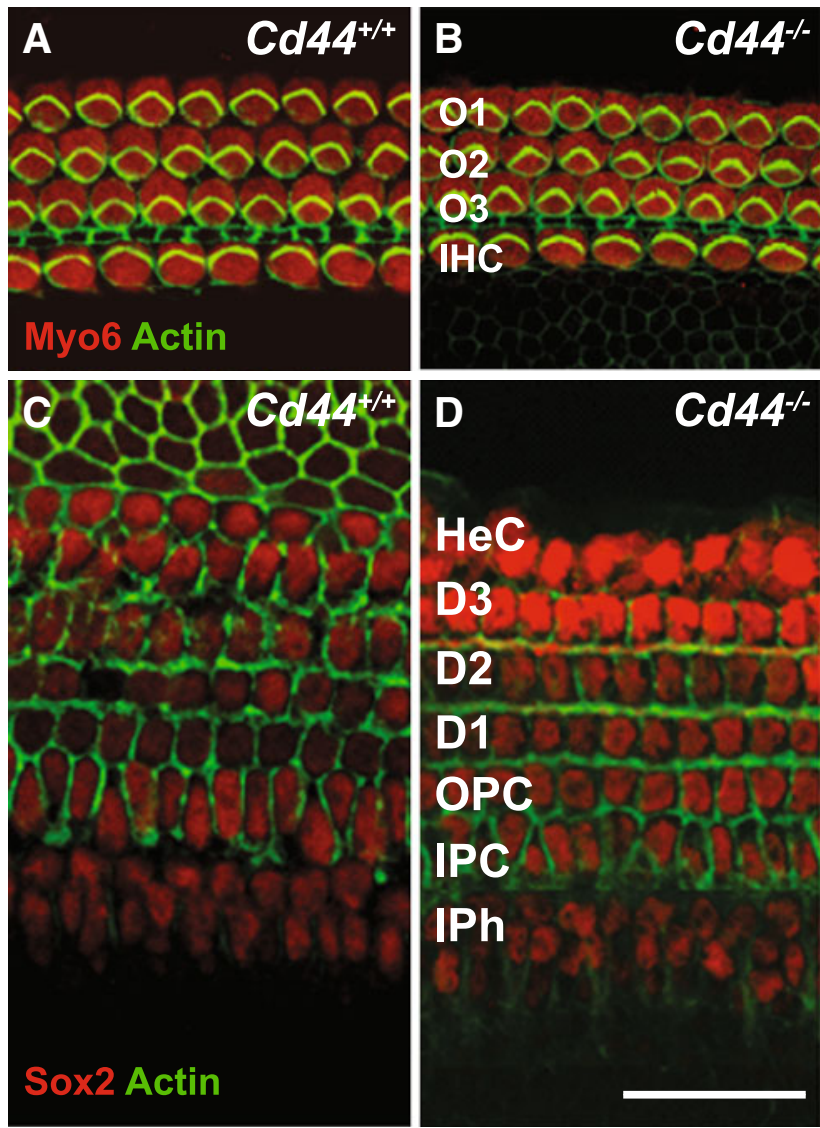

FIG. 5. Whole-mount labeling of P2 cochleae from $C D 44^{+/+}(\mathbf{A}, \mathbf{C})$ and $C D 44^{-1}$ (B, D) mice with phalloidin to detect actin (green), an antibody for myosin $\mathrm{VI}$ (red) to detect hair cells (A, B) and Sox2 (red) to detect supporting cell nuclei $(\mathbf{C}, \mathbf{D})$. Both hair cells and supporting cells including pillar cells develop normally in the absence of CD44. No obvious morphologic abnormalities are seen. O1-O3 outer hair cells, IHC inner hair cells, HeC Hensen's cells, D1-D3 Deiters' cells, $O P C$ outer pillar cell, IPC inner pillar cell, IPh inner phalangeal cell. Scale bar, $23 \mu \mathrm{m}(\mathbf{A}, \mathbf{B}) ; 50 \mu \mathrm{m}(\mathbf{C}, \mathbf{D})$.

sensory epithelia are yet to be fully differentiated (reviewed in Kelley 2007). Our research focus was to identify novel cochlea-specific markers. In addition, our semi-quantitative real-time RT-PCR assays addressed differential patterns of gene expression in the discrete vestibular patches (utricle, saccule, and cristae). This study is unique in its attempt to differentially quantify a large set of genes in the distinct vestibular patches using semi-quantitative real-time RT-PCR.

Our analysis identified two markers that were uniquely enriched in the cochlear sensory epithelium, $\mathrm{CD} 44$ and Fgfr3. Interestingly, the real-time RT-PCR analysis revealed several patterns of vestibular epithelia gene expression. A small subset of genes were specifically enriched both in the cochlear and saccular sensory epithelia. These included CD10,CD26,CD56,CD83, CD91, CD106, CD140a, CD140b, CD248, and CD302. In contrast, none of the genes were uniquely enriched either in the cochlear and utricular epithelia or in the cochlear epithelium and the epithelia of the cristae ampullaris. Indeed, a very small number of markers were specifically enriched in the epithelia of the cristae ampullaris. Further localization of these proteins by immunohistochemistry will shed light on the functional significance of these results.

While hair cells have multiple cell type-specific markers that are expressed from early developmental stages and persist to adulthood, e.g., myosin VI (Hasson et al. 1997), myosin VIIa (Hasson et al. 1995), Pou4f3 (Xiang et al. 1998), and prestin (Belyantseva et al. 2000), similar cell type-specific markers for supporting cells have not been identified. Moreover, while the supporting cells differ in structure and function, most of the supporting cell-specific markers are shared by at least two cell types. For example, SOX2, a transcription factor, labels six different support cell types within the cochlea including pillar cells, while a different transcription factor, PROX1, labels pillar cells and Deiters' cells (Hume et
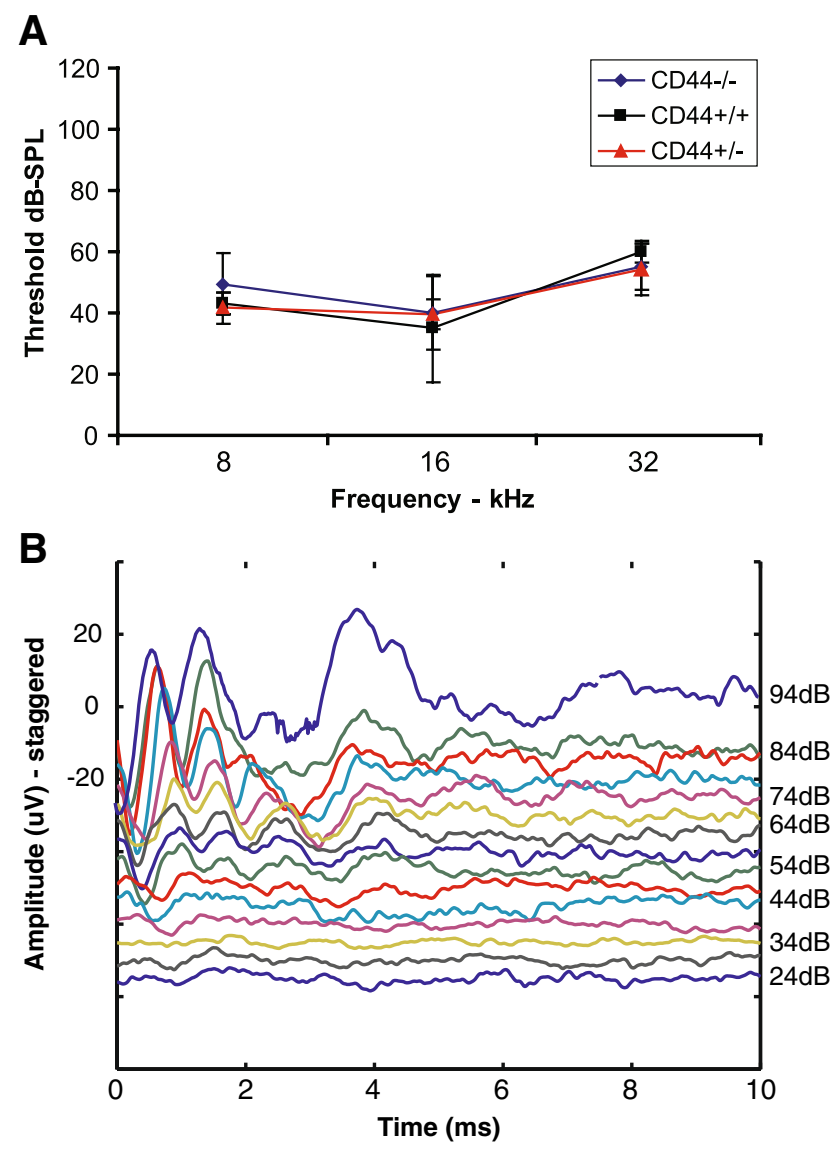

FIG. 6. Hearing thresholds as measured by ABR from 6-week-old $\mathrm{CD} 44^{+/+}, \mathrm{CD} 44^{+/}$, and $\mathrm{CD} 44^{-/}$mice. No significant difference in threshold is detected between the three genotypes (A). ABR tracings obtained at $16 \mathrm{kHz}$ from a 5 -month-old $\mathrm{CD}_{4} 4^{-}$mouse (B). As in $\mathbf{A}$, no significant loss of hearing was observed. 
al. 2007). Previous studies have also identified FGFR3, a cell surface marker, as expressed by developing pillar and Deiters' cells (Mueller et al. 2002).

We have identified CD44 as the first outer pillar cellspecific marker in the early postnatal mouse inner ear. Like many other supporting cell markers, the expression of CD44 is not limited to the outer pillar cells. However, the lack of CD44 staining in other cells immediately adjacent to the outer pillar cells within the sensory epithelium, makes it an ideal marker for the outer pillar cells in the early postnatal period. CD44 is an integral cell membrane glycoprotein with a diverse range of suggested functions (MIM 107269). The principal ligand of CD44 is hyaluronic acid, an extracellular matrix protein (Aruffo et al. 1990). CD44 has been primarily studied as a receptor expressed on activated T cells and is known as a lymphocyte homing receptor (Aruffo et al. 1990; Stefanova et al. 1989). By binding hyaluronic acid, CD44 can facilitate extravasation of lymphocytes at sites of inflammation. Other identified ligands include laminin, fibronectin, collagens, serglycin, and osteoponin (reviewed in Goodison et al. 1999). CD44 consists of extracellular, transmembrane, and intracellular domains. The mouse CD44 consists of nine constant exons that flank ten variable exons. The transmembrane and intracellular domains of CD44 are encoded by the constant exons, while the alternatively spliced exons affect the structure of the extracellular domain (Goodison et al. 1999). Specific splice variants of the protein have since been implicated in malignant transformation, cancer metastasis, and inflammatory diseases (reviewed in Bourguignon 2008; Johnson and Ruffell 2009; Liu and Jiang 2006). The expression of CD44 has also been described in multiple morphogenetically active epithelia as well as in Muller cell apical microvili in the retina (Stefanova et al. 1989; $\mathrm{Yu}$ and Toole 1997). Using in situ hybridization, CD44 v4-7, v4-5, v6-7, v8-10, and the short isoform were detected in E15 inner ears (Yu and Toole 1997). Our results show that by $\mathrm{P} 0$, the expression of the short isoform of $C D 44$ as well as $C D 44 v 8-10$ persists. CD44 v6 10 and $v 9-10$ could also be detected. Other isoforms were not found, and it is possible that they are expressed only at earlier developmental stages.

CD44 KO mice are viable and do not display obvious developmental defects, but do suffer from specific alterations in their lymphocyte-dependent immune responses (Protin et al. 1999; Schmits et al. 1997). Our results show that in the absence of CD44, the mouse inner ear develops normally and that ABR hearing thresholds are comparable to wild-type and heterozygous littermates. In addition, specific blocking experiments of cochlear explant cultures harvested at E14.5 and incubated with a blocking antibody for CD44 did not result in any discernable phenotype until a toxic dose was reached (data not shown). Therefore, the specific role of CD44 and its isoforms in the mouse inner ear remains to be determined. Furthermore, as we could not identify mutations in CD44 among the human DFNB51 families, mutations of $C D 44$ appear not to have a role in human hereditary hearing loss.

Finally, the mammalian auditory and vestibular sensory epithelia are highly complex and composed of a variety of tightly organized cell types. Recently, mice with transgenic expression of a green fluorescent protein (GFP) under the regulation of general supporting cell-specific $\left(p 2 \gamma^{k i p 1}\right)$ or hair cell-specific (Atoh1) promoters were used to isolate these mixed cell populations, respectively (Doetzlhofer et al. 2006; White et al. 2006). Similarly, mice with cell type-specific GFP expression have been used to isolate and characterize the transcriptomes of specific cell populations from the brain and the retina (Ivanov et al. 2008; Lobo et al. 2006; Marsh et al. 2008). Antibodies to CD proteins are routinely used for FACS analysis of leukocytes, routine diagnostics of hematologic diseases, and for staining pathology slides for cancer diagnostics. Our results indicate that multiple $\mathrm{CD}$ genes are expressed in the mouse auditory and vestibular sensory epithelia, and suggest that at least some of these proteins may have differential expression patterns in the inner ear, similar to CD44. By further characterizing the expression pattern of other CD genes in the mouse inner ear, it may be possible to devise protocols for cell type-specific sorting from wild-type mice. This would allow for comparative analysis of inner ear cell typespecific expression profiles of wild-type and mutant mice and could assist in the identification of new deafness genes.

\section{ACKNOWLEDGEMENTS}

We are grateful to Janice K. Babus, Yadong Ji, Amiel A. Dror and Dr. Weise Chang for technical assistance, Dr. Suzi Mansour and Chaoying Li for sending us the Fgfr3-P244R mutant mice. We thank Dr. Karen B. Avraham for sharing unpublished data, and Dr. Tomoko Makishima for critically reviewing this manuscript. Finally, we thank Dr. Strome's laboratory members for their technical help and advice. This research was supported by a resident research grant provided by the American Academy of OtolaryngologyHead and Neck Surgery Foundation (R.H.), a Deafness Research Foundation grant (R.H.) and by funds from the Intramural Program at NIDCD 1-Z01-000070 (M.W.K), and 1-Z01-000039 (T.B.F).

\section{REFERENCES}

Ahmed ZM, Riazuddin S, Bernstein SL, Ahmed Z, Khan S, Griffith AJ, Morell RJ, Friedman TB, Wilcox ER (2001) Mutations of the 
protocadherin gene PCDH15 cause Usher syndrome type 1F. Am J Hum Genet 69:25-34

Aruffo A, Stamenkovic I, Melnick M, Underhill CB, Seed B (1990) CD44 is the principal cell surface receptor for hyaluronate. Cell 61:1303-1313

Beare A, Stockinger H, Zola H, Nicholson I (2008) Monoclonal antibodies to human cell surface antigens. Curr Protoc Immunol Appendix 4:4A

Belyantseva IA, Adler HJ, Curi R, Frolenkov Gi, Kachar B (2000) Expression and localization of prestin and the sugar transporter GLUT-5 during development of electromotility in cochlear outer hair cells. J Neurosci 20:RC116

Bourguignon LY (2008) Hyaluronan-mediated CD44 activation of RhoGTPase signaling and cytoskeleton function promotes tumor progression. Semin Cancer Biol 18:251-259

Colvin JS, Bohne BA, Harding GW, McEwen DG, Ornitz DM (1996) Skeletal overgrowth and deafness in mice lacking fibroblast growth factor receptor 3. Nat Genet 12:390-397

Dabdoub A, Puligilla C, Jones JM, Fritzsch B, Cheah KS, Pevny LH, KeLLey MW (2008) Sox2 signaling in prosensory domain specification and subsequent hair cell differentiation in the developing cochlea. Proc Natl Acad Sci USA 105:1839618401

Doetzlhofer A, White P, Lee YS, Groves A, Segil N (2006) Prospective identification and purification of hair cell and supporting cell progenitors from the embryonic cochlea. Brain Res 1091:282-288

Doetzlhofer A, Basch ML, Ohyama T, Gessler M, Groves AK, Segil N (2009) Hey2 regulation by FGF provides a Notch-independent mechanism for maintaining pillar cell fate in the organ of Corti. Dev Cell 16:58-69

Dror AA, Avraham KB (2009) Hearing loss: mechanisms revealed by genetics and cell biology. Annu Rev Genet 43:411-437

Forge A, Wright T (2002) The molecular architecture of the inner ear. Br Med Bull 63:5-24

Goodison S, Urouidi V, TARin D (1999) CD44 cell adhesion molecules. Mol Pathol 52:189-196

Hasson T, Heintzelman MB, Santos-Sacchi J, Corey DP, Mooseker MS (1995) Expression in cochlea and retina of myosin VIIa, the gene product defective in Usher syndrome type 1B. Proc Natl Acad Sci USA 92:9815-9819

Hasson T, Gillespie PG, Garcia JA, MacDonald RB, Zhao Y, Yee AG, MOOSEKER MS, COREY DP (1997) Unconventional myosins in inner-ear sensory epithelia. J Cell Biol 137:1287-1307

Hayashi T, Cunningham D, Bermingham-McDonogh O (2007) Loss of Fgfr3 leads to excess hair cell development in the mouse organ of Corti. Dev Dyn 236:525-533

Hertzano R, Montcouquiol M, Rashi-Elkeles S, Elkon R, Yucel R, Frankel WN, Rechavi G, Moroy T, Friedman TB, Kelley MW, Avraham KB (2004) Transcription profiling of inner ears from Pou4f3(ddl/ddl) identifies Gfil as a target of the Pou4f3 deafness gene. Hum Mol Genet 13:2143-2153

Herzenberg LA, De Rosa SC (2000) Monoclonal antibodies and the FACS: complementary tools for immunobiology and medicine. Immunol Today 21:383-390

Hume CR, Bratt DL, Oesterle EC (2007) Expression of LHX3 and SOX2 during mouse inner ear development. Gene Expr Patterns 7:798-807

Ivanov D, Dvoriantchikova G, Barakat DJ, Nathanson L, Shestopalov VI (2008) Differential gene expression profiling of large and small retinal ganglion cells. J Neurosci Methods 174:10-17

Johnson P, Ruffell B (2009) CD44 and its role in inflammation and inflammatory diseases. Inflamm Allergy Drug Targets 8:208-220

Kelley MW (2007) Cellular commitment and differentiation in the organ of Corti. Int J Dev Biol 51:571-583

Liu J, Jiang G (2006) CD44 and hematologic malignancies. Cell Mol Immunol 3:359-365
Lobo MK, Karsten SL, Gray M, Geschwind DH, Yang XW (2006) FACS-array profiling of striatal projection neuron subtypes in juvenile and adult mouse brains. Nat Neurosci 9:443-452

Mansour SL, Twigg SR, Freeland RM, Wall SA, Li C, Wilkie AO (2009) Hearing loss in a mouse model of Muenke syndrome. Hum Mol Genet 18:43-50

Marsh ED, Minarcik J, Campbell K, Brooks-Kayal ar, Golden JA (2008) FACS-array gene expression analysis during early development of mouse telencephalic interneurons. Dev Neurobiol 68:434-445

McKenzie E, Krupin A, Kelley MW (2004) Cellular growth and rearrangement during the development of the mammalian organ of Corti. Dev Dyn 229:802-812

Montcouguiol M, CoRwin JT (2001) Intracellular signals that control cell proliferation in mammalian balance epithelia: key roles for phosphatidylinositol-3 kinase, mammalian target of rapamycin, and S6 kinases in preference to calcium, protein kinase $\mathrm{C}$, and mitogenactivated protein kinase. J Neurosci 21:570-580

Morrison A, Hodgetts C, Gossler A, Hrabe de Angelis M, Lewis J (1999) Expression of Deltal and Serrate1 (Jagged1) in the mouse inner ear. Mech Dev 84:169-172

Mueller KL, JacQues BE, Kelley MW (2002) Fibroblast growth factor signaling regulates pillar cell development in the organ of Corti. J Neurosci 22:9368-9377

Pannier S, Couloigner V, Messaddeg N, Elmaleh-Berges M, Munnich A, Romand R, Legeai-Mallet L (2009) Activating Fgfr3 Y367C mutation causes hearing loss and inner ear defect in a mouse model of chondrodysplasia. Biochim Biophys Acta 1792:140-147

Peters K, Ornitz D, Werner S, Williams L (1993) Unique expression pattern of the FGF receptor 3 gene during mouse organogenesis. Dev Biol 155:423-430

Protin U, Schweighoffer T, Jochum W, Hilberg F (1999) CD44-deficient mice develop normally with changes in subpopulations and recirculation of lymphocyte subsets. J Immunol 163:4917-4923

Puligilla C, Feng F, Ishikawa K, Bertuzzi S, Dabdoub A, Griffith AJ, Fritzsch B, Kelley MW (2007) Disruption of fibroblast growth factor receptor 3 signaling results in defects in cellular differentiation, neuronal patterning, and hearing impairment. Dev Dyn 236:1905-1917

Raphael Y, Altschuler RA (2003) Structure and innervation of the cochlea. Brain Res Bull 60:397-422

Schmits R, Filmus J, Gerwin N, Senaldi G, Kiefer F, Kundig T, Wakeham A, Shahinian A, Catzavelos C, Rak J, Furlonger C, Zakarian A, Simard JJ, Ohashi PS, Paige CJ, Gutierrez-Ramos JC, MAK TW (1997) CD44 regulates hematopoietic progenitor distribution, granuloma formation, and tumorigenicity. Blood 90:2217-2233

Shaikh RS, Ramzan K, Nazli S, Sattar S, Khan SN, Riazuddin S, Ahmed ZM, FriEdman TB (2005) A new locus for nonsyndromic deafness DFNB51 maps to chromosome 11p13-p12. Am J Med Genet 138:392-395

Spring FA, Dalchau R, Daniels GL, Maluinson G, Judson Pa, Parsons SF, Fabre JW, Anstee DJ (1988) The Ina and Inb blood group antigens are located on a glycoprotein of 80, 000 MW (the CDw44 glycoprotein) whose expression is influenced by the In (Lu) gene. Immunology 64:37-43

Stefanova I, Hilgert I, Bazil V, Kristofova H, Horejsi V (1989) Human leucocyte surface glycoprotein CDw44 and lymphocyte homing receptor are identical molecules. Immunogenetics 29:402-404

White PM, Doetzlhofer A, Lee YS, Groves AK, Segil N (2006) Mammalian cochlear supporting cells can divide and transdifferentiate into hair cells. Nature 441:984-987

XIAng M, GaO WQ, Hasson T, Shin JJ (1998) Requirement for Brn-3c in maturation and survival, but not in fate determination of inner ear hair cells. Development 125:3935-3946

YU Q Toole BP (1997) Common pattern of CD44 isoforms is expressed in morphogenetically active epithelia. Dev Dyn 208:1-10 